The International Journal of Engineering and Science (IJES)

|| Volume || 6 || Issue || 4 || Pages || PP 48-57 || 2017 ||

ISSN (e): $2319-1813$ ISSN (p): $2319-1805$

\title{
Strategies to Overcome Fatigue in Air Traffic Control Based on Stress Management
}

\author{
Iva Tomic ${ }^{1}$, Jixin Liu ${ }^{2}$ \\ ${ }^{1,2}$ College of Civil Aviation, Nanjing University of Aeronautics and Astronautics, Nanjing, 211106,China
}

\begin{abstract}
Safety and health at work are extremely important, yet they still appear to be one of the most neglected factors in the aviation industry. Almost $90 \%$ of accidents that occur in the workplace are due to human errors. While studies suggest that the lack of skills and experience among workers can significantly increase the prevalence of human errors, few studies actually investigate how stress and fatigue can affect human error. Hence, this study aims to explore the significance of the effects of stress and fatigue and work on human error in aviation industry. Questionnaires were developed and distributed to several air traffic control units across China and Eastern Europe. A total of 73 questionnaire responses were collected. The responses were analyzed using IBM SPSS Statistics. It was found that fatigue and stress play a major role in the work of air traffic controllers. Research showed that pressure with $58.90 \%$, fatigue with a total of $60.30 \%$, and shift work with $76.70 \%$ are the main stressors among ATCOs. The results of this study are highlighting main areas of concern and can act as useful guidance for further research.
\end{abstract}

Keywords: Air traffic control, Stress management, Stress, Fatigue, Fatigue risk management system

Date of Submission:07 April 2017 Date of Accepted: 18 April 2017

\section{INTRODUCTION}

Work-related stress is a major concern in all occupations and it is affecting not only employees whose health is at stake but also organizations. It is forecasted that by the year of 2035 the total growth of air traffic will be at an average of 6.2 percent. This forecast shows us that demands for staffing of air traffic controllers in the next 20 years will rapidly grow as well as stress and fatigue levels of current air traffic controllers worldwide, as they have to ensure safety of those using air transportation services. Stress affects performance of air traffic controllers and their abilities to complete their tasks properly. Too much stress affects controller ability to focus and concentrate on a certain task which can lead to catastrophic events, such as aviation incidents and accidents. On the other side, fatigue presents a minor inconvenience that is most commonly resolved with a nap or by stopping activity that caused fatigue. Typically, there are no significant consequences of fatigue. However, if that person is involved in safety-related activities such as piloting an aircraft, or separating aircraft and being in charge of a safe air traffic flow, the consequences of fatigue can be disastrous. The purpose of this paper is to find correlation between stress and fatigue as well as identify the main causes of fatigue and stress, and to find gaps in previous studies on the same topic in order to highlight areas of concern and possibly find some solutions and recommendations that can help air traffic controller as well as other groups.

\section{DEFINITION OF STRESS}

Stress has grown rapidly in recent years. It is therefore of some importance to investigate whether or not there is an epidemic of stress, what is causing it and whether it will continue to rise. The attention goes to the questions such as why stress is occurring, and what is happening in society, contemporary life and current working practices that are causing stress. Stress refers to our response to extreme pressure, hardship, or pain that either occurs suddenly or builds up over time.

Different authors and theorists have developed their own definitions based on their own research. It should be noted that, stress, as a word usually has negative connotation and conveys negative effects (for example, headaches, insomnia). However, stress can be both positive and negative. It is necessary to point that there are differences between stressors causing distress (a negative response) and those causing eustress (a positive response). Stress is physiological, psychological and behavioral response by the individual, when they distinguish imbalance between the demands upon them and their own ability to fulfill these demands (Palmer, 1999). [1] A very simple way to define stress is, "Stress occurs when pressure exceeds your perceived ability to cope" (Palmer, 1999). 
Work-related stress can be defined as the harmful physiological and psychological responses that occur when the requirements of the job do not match the capabilities, resources, or needs of the worker. When challenge is met, we feel relieved and satisfied. Sometimes the challenge turns into job demand that cannot be met, relaxation turns into exhaustion, and a sense of satisfaction turns into feelings of stress.

\subsection{Models of stress}

Stress can be caused by different factors and symptoms of stress can manifest themselves physiologically, psychologically or behaviorally. However, stress can affect different people in very different ways. It often depends on the relationship that exists between individuals themselves and the working environment. Differences in personality type can affect the way in which people are affected by stress. Two main types of personality are type A personality and type B personality. Individuals that are considered to be type A tend to be more impatient, easily irritated, competitive, and aggressive, while type B individuals tend to be less competitive, more casual and never rushed. (Cox, 1995) [2] Identified three models of stress: Response-based model works on the theory that stress is a response to a 'stressor' such as work overload. Stimulus-based model states that stress is a response to environmental variables, such as excess noise or cold. Individuals are able to tolerate certain levels of stress but once this is exceeded, permanent damage, either physiological or psychological, will occur. This model identifies the sources of stress in the work environment. Interactive model of a stress incorporates factors from both response and stimulus based models, plus outside factors such as personality.

\subsection{Sources and duration of stress}

Individuals experience stress from four basic sources: environmental stressors such as weather, noise, crowding, traffic etc.; social stressors which include deadlines, job interviews, presentations, disagreements, demands for your time and attention etc.; psychological stressors include illness, aging, accidents, lack of exercise, poor nutrition, and sleep disturbances etc.; and thoughts where our brain interprets and perceives situations as stressful, difficult, painful, or pleasant. Some situations in life are stress provoking, but it is our mind that determines whether they present threat or not. Situations that are considered stress provoking are known as stressors. Many professionals suggest that there is a difference between what we perceive as positive stress and distress, which refers to negative stress. Table 1 shows us some characteristics of positive and negative stress.

Table 1 Characteristics of positive and negative stress

\begin{tabular}{|l|l|}
\hline Positive stress & Negative stress \\
\hline Motivates, focuses energy & Causes anxiety or concern \\
\hline It is short- term & Can be short or long -term \\
\hline Is perceived as within our coping abilities & Is perceived as outside of our coping abilities \\
\hline Feels exciting & Feels unpleasant \\
\hline Improves performance & Decreases performance \\
\hline
\end{tabular}

The duration of stressful event or situation defines whether the stress is acute or chronic. Physiological and psychological reactions to these types of stress can be very different.

Acute stress is the most common form of stress. It comes from demands and pressures off the recent past and anticipated demands and pressures of the near future. Acute stress is caused by stressors that occur for very short period of time. Acute stress can be positive, trilling and exciting in small doses but extremely high levels of over-arousal for short durations can lead to exhaustion. The most common symptoms are:

- Behavioral - some combination of anger or irritability, anxiety and depression etc.

- Physiological - headache, back pain, muscular tension, stomach, gut and bowel problems, elevation in blood pressure, rapid heartbeat, sweaty palms.

Chronic stress comes when a person doesn't see a way out of a miserable situation. It is caused by constant stream of demand, risks, pressures and threats that go on for significantly long period of time. It slowly drains psychological and physiological resources and leaves a sense of hopelessness or inability to cope. The most dangerous aspects of chronic stress are that because it is prolonged, an individual may stop noticing its effects even through the negative effects are still taking place.

\subsection{Stress-released hazards}

Most stressful type of work is the one which values excessive demands and pressures that are not matched to worker's knowledge and abilities, where there is a little opportunity to exercise any choice or control, and where there is a little support from others. The literature on stress generally recognizes nine categories of stress-released hazards and they are listed below in table 2 . 
Table 2 Nine categories of stress-released hazards

\begin{tabular}{|l|l|}
\hline Job content & $\begin{array}{l}\text { Monotones, meaningless tasks, lack of variety, unpleasant tasks, } \\
\text { aversive tasks }\end{array}$ \\
\hline Workload & Having too much or too little to do, working under time pressure \\
\hline Working hours & $\begin{array}{l}\text { Strict an inflexible working schedules, long and unsocial hours, } \\
\text { unpredictable working hours, badly designed shift systems }\end{array}$ \\
\hline Career development, status and pay & $\begin{array}{l}\text { Lack of participation in decision making, lack of control (for } \\
\text { example, over work methods, work pace, working hours and } \\
\text { working environment) }\end{array}$ \\
\hline Role in the organization & $\begin{array}{l}\text { Job insecurity, lack of promotion prospects, under-promotion or } \\
\text { over-promotion, work of 'low social value', piece rate payment } \\
\text { schemes, unclear or unfair performance evaluation systems, being } \\
\text { over-skilled or under-skilled for the job }\end{array}$ \\
\hline Interpersonal relationships & $\begin{array}{l}\text { Unclear role, conflicting role within the same job, responsibility } \\
\text { for people, continuously dealing with other people and their } \\
\text { problems }\end{array}$ \\
\hline Organizational culture & $\begin{array}{l}\text { Inadequate, inconsiderate or unsupportive supervision, } \\
\text { relationship with co-workers, bullying, harassment and violence, } \\
\text { isolated or solitary work, no agreed procedures for dealing with } \\
\text { problems or complains }\end{array}$ \\
\hline Home-Work interface & $\begin{array}{l}\text { Poor communication, poor leadership, lack of clarity about } \\
\text { organizational objectives and structure }\end{array}$ \\
\hline $\begin{array}{l}\text { Conflicting demands of work and home, lack of support for } \\
\text { domestic problems at work, lack of support of work problems at } \\
\text { home. }\end{array}$
\end{tabular}

\subsection{Workplace interventions and strategies for the management of stress}

Despite widespread recognition that stress is an important issue and its upsetting consequences to people's lives and performance at work, not all organizations have given the attention it deserves. (Dewe et al., 2010) [3] Noted that the level of attention given by the organizations to addressing stress-related issues is still relatively small compared with their investments in other areas such as financial budgeting, marketing and technological development. Workplace interventions and strategies for the management of stress can typically be categorized into three groups: primary, secondary, and tertiary.

Primary management strategies aim to prevent work-related stress arising, targeting the employees, the job or the interface between the worker and the workplace, for example job redesign, work-load reduction, improved communication, conflict management skill development etc.

Secondary approaches attempt to minimize the impact of stress and diminish the seriousness of its consequences, and therefore tend to focus on the individual worker. Most commonly used methods are cognitive behavioral therapy, copying classes and anger management.

Tertiary stress management strategies involve identifying and treating the ill effects of stress once they have occurred, and rehabilitating the individuals to enable them to return to work as quickly as possible. Most frequently used interventions include return-to-work programs, employee assistant programs, occupational therapy, and medical stress intervention.

\section{FATIGUE}

The ability to manage human fatigue in transport operations would be improved by a shared understanding of what fatigue is, how it should be measured, and how it affects safety performance. Fatigue should be measured in terms of experience and physiological state and performance. In studying the effects of fatigue on individuals, there would be a need for greater consideration of its long-term effects, and its motivational aspects. To understand its performance effects it would require that we attend to the systematic interaction of sleep history, time of a day, time at work, and time on task, in the context of factors describing various aspects of work and non-work life.

Fatigue has multidimensional aspects, which are dynamically interdependent and which do not fully correlate. The context of exertion is described by the value and meaning of performance to the individual; rest and sleep history; circadian effects; psychosocial factors spanning work and home life; individual traits; diet; health; fitness and other individual states; and environmental conditions.

Human fatigue has been indicated as a causal factor in some significant aircraft accidents. In commercial aviation operations, about $70 \%$ of fatal accidents are related to human error.

\subsection{Factor influencing controller's fatigue}

Research has identified work, non-work, and biological related factors that influence sleep and fatigue in ATCOs. Factors such as shift work, shift length, type of work being performed, workload, working environment, break 
frequency, sleep disorders, individual factors, age, circadian rhythms, and family responsibilities are all influencing ATCOs fatigue.

\subsubsection{Shiftwork}

Aviation industry has 24-hour-a-day air traffic control operational requirements, thereby requiring some controllers to work overnight. Shiftwork has the potential to disrupt the circadian rhythms and impair work performance, raising concerns for the safe operation of air traffic control. (Costa, 1999; Meyer, 1973) [4][5]. Great deal of attention has been focused on how shiftwork and schedules result in fatigue, and on how they affect performance, sleep, mood, and health of ATCOs.) ATCs working at night are at the nadir of their circadian rhythms, which results in fatigue, sleepiness, and performance decrements; shift schedules often create sleep debt, which reduces alertness and performance, particularly during night shifts and at the beginning of early morning shifts. Many studies observed that ATCs reported more sleepiness during the night shift, compared to day or evening shifts (Cruz and Della Rocco, 1995; Grandjean et al., 1971; Rhodes et al., 1996),[6][7][8] peaking in the early morning hours in some cases (Costa, 1999; Luna, 1997). It is also worth mentioning that low traffic load occurring during night shift contributes to increased fatigue and sleepiness in ATCs (Luna, 1997; Wickens, Mavor, and McGee, 1997) [9][10].

The sleepiness and fatigue reported by ATCs can be attributed to the circadian trough occurring at night, but also to sleep deprivation and its associated sleep debt. For the shift-worker, night shifts entail sleeping during the day. Because of the diurnal orientation of social life, circadian rhythms ATCs working at night get the shortest amount and poorest quality of sleep. Fatigue, sleepiness, circadian trough, sleep deprivation, low traffic load, and low lighting levels were all identified as factors contributing to decreased performance and vigilance at night (Benson, 1970; Costa, 1993; Costa, 1999;)[11][12].

\subsubsection{Scheduling}

Scheduling is a sensitive topic and a satisfactory solution to optimal scheduling system for all air traffic control situations remains elusive. Permanent schedules involve always working the same shift. The slow rotation schedule, a variation of permanent schedule, involves working five straight days on a specific shift, then rotating to another shift the following week. Other schedules imply rapid rotation of shifts during the week. Although the exact configuration may vary, two main kinds of rapid rotation schedule exist: clockwise rotation, and counter-clockwise rotation. In clockwise rotation the work week starts with a day shift, rotating later in the week to an afternoon shift, and finally changing to night shift. In the counter-clockwise rotation, the work week starts with afternoon shift, then advances to an early day shift, to finally end with the night shift. The NTSB has expressed concerns regarding ever changing shift cycle because it limits the amount of time for res between shifts.

\subsubsection{Workload and time on task}

Workload is experienced differently between ATCOs which depends on experience, skills, motivation, tiredness, and also on their coping skills (Hopkin, 1995; Wickens et al., 1997)[13]. High workload related to high traffic volume eventually creates fatigue because of the sustained efforts required (Meyer, 1973). The efforts needed to cope with high workload can only be sustained for a certain period of time and they affect performance of the individual. Air traffic controllers experience mental demand as a source of workload. Mental demand is a concept which is connoted to the general cognitive operations of thinking, deciding, and mental arithmetic, remembering and searching. Both overload and under load have the same effect of stress in air traffic control. In high working conditions operators' cognitive capacity to attend to multiple cues become limited due to work intensity, and that in low workload operators may reduce their vigilance to the point that they attend to cues ineffectively, or fail to seek out the cues necessary for situational awareness.

\subsubsection{Personal characteristics and individual differences}

ATCs that have healthy habits such as exercising, a balanced diet, good sleep hygiene, and good time management strategies cope more effectively with fatigue (Costa, 1999; Meyer, 1973; Rhodes et al., 1994). [14]On the other side those individuals that have bad habits such as drinking too much coffee and alcohol, smoking, having poor eating habits, taking medication show more illness indication and have poorer coping mechanism.

Coping with shiftwork, fatigue, and stress becomes increasingly difficult with age, mainly because older ATCs are less resistant to stress, get less sleep, and their circadian rhythms are more easily disrupted by unstable sleep patterns (Costa, 1999; Costa et al., 1995; Rhodes et al., 1996) [15].

Personality characteristics and behavioral aspects also influence the impact of fatigue on individuals. Whether ATCs are morning or evening types can influence performance and adaptation to shifts. Morning-type ATCs have more difficulty coping with night work, but they cope more easily with early morning hours, while evening types, as can be expected, cope more easily with evening and night shifts (Costa, 1999; Costa et al., 1995; Rhodes et al., 
1994). Overall, evening types cope better with shiftwork since they show less sleep disruption with shiftwork and also lowered levels in physiological indicators associated with stress (Costa, 1993, 1999).

\subsection{Fatigue risk management system}

Fatigue is a major human factors hazard because it affects most aspects of the air traffic controls ability to do their job. ICAO defines a Fatigue Risk Management System (FRMS) as: A data-driven means of continuously monitoring and managing fatigue-related safety risks, based upon scientific principles and knowledge as well as operational experience that aims to ensure relevant personnel are performing at adequate levels of alertness.

An FRMS aims to ensure that air traffic controllers and flight crew members are sufficiently alert so they can insure safe level of performance. It applies principles and processes from Safety Management Systems (SMS) 1 to manage the specific risks associated with crewmember and ATCOs fatigue. It is a data-driven, risk-informed, safety performance-based program that reduces the risk of fatigue-related incidents in 24/7 operations.[16]

\section{COORELATION BETWEEN STRESS AND FATIGUE}

When we are stressed, our body produces a hormone called cortisol. Cortisol increases the amount of adrenaline produced by our adrenal glands, which pumps us up and kicks in our "fight or flight" response. Our body produces adrenaline, our metabolism speeds up in order to produce more energy. This enhanced energy output uses up all of the glucose we have stored, leaving our body drained of resources. When the energy is all gone, we feel tired and sleepy-hence the link between stress and fatigue.

As already noted before, ATCOs are mostly exposed to mental fatigue due to constant stream of demans, solving stressful life threating situations end much more. If individual is exposed to a constant stream of pressure, deadlines, risks it will eventually lead to fatigue.

If ATCO is experiencing fatigue for some period of time his operational abilities such as reaction time, alertness decision making, judgment and concentration will be receded which will eventually lead to stress due to inanity to meet the demands.

Common risk factor patterns could be identified according to socio-economic status and self-perceived health status: the lower the health status the higher the risk for stress and fatigue. As in comparable studies, women report higher fatigue than men. Fatigue could be a stress-related disorder triggered by long lasting tension. Therefore, this relation deserves more research attention, particularly with regard to unexplained fatigue.

\section{RESEARCH SURVEY}

The aim of this survey was to investigate how air traffic controllers cope with stress and fatigue in their occupation and also to determinate causes of stress and fatigue.

The study was conducted on a valid sample of 73 Air Traffic Controllers who control civilian aircraft in Chinese and part of European airspace. Questionnaire was used to collect data and analyzed to determinate which stressors affect controllers the most as well as their coping strategies to overcome stress and fatigue. The objective of this research is to evaluate the relationship between stress and fatigue and the procedures implemented by aviation companies to minimize their effect on the employees. This research was exploratory in nature because of the limitation in size and scope. The questionnaires have been designed for Area controllers in China and Eastern Europe and it was developed based on literature review and previous studies on a same topic. One questionnaire was designed to collect data about stress and it contained 2 parts in which controllers could choose one of the given options or write their own opinion for a certain question. The other questionnaire has been designed to collect data related to fatigue among ATCs. It contained 3 parts in which controllers could choose answers that fit the best in description of their current stage of fatigue as well as their opinions on certain questions. Questionnaires were strictly anonymous and the only personal information shared was age, gender and country. The survey was conducted from June 2016 to October 2016. A total of 80 Air traffic controllers were sampled and 75 questionnaires returned, from which 73 are valid. Table 3 shows information about responders.

Table 3 Descriptive statistics: Age, Gender and Region

\begin{tabular}{|l|l|l|}
\hline Age & Number of ATCOs & Percentage of ATCOs \\
\hline 22-30 & 25 & $34.2 \%$ \\
$\mathbf{3 1 - 6 0}$ & 48 & $65.8 \%$ \\
Total & 73 & $100 \%$ \\
\hline Gender & & \\
Male & 49 & $67.1 \%$ \\
Female & 24 & $32.9 \%$ \\
Total & 73 & $100 \%$ \\
\hline Region & & \\
Asia-China & 43 & $58.9 \%$ \\
Europe & 30 & $41.1 \%$ \\
Total & 73 & $100 \%$ \\
\hline
\end{tabular}




\subsection{Analysis of collected data}

Statistical analysis was computed using IBM SPSS Statistics, Version 20. Frequency analysis was used to investigate the differences between genders, age, and region. Descriptive analysis was used to provide data for total sample.

In answering the question of "Are you currently experiencing any signs of stress?", 73 air traffic controllers replied as fallowed, $53.1 \%$ of male air traffic controllers said that they are currently experiencing some signs of stress, and $70.8 \%$ of female air traffic controllers that were part of the questionnaire said yes on the same question. For more details please check table 4 below. As seen from the table, stress plays its part in work of air traffic controllers. From the table, we can also notice that women reported feeling stressed more than man. This doesn't necessary mean that women are more easily stressed, as women are more likely than men to report physiological and psychological symptoms of stress. Another component that we need to take into consideration is work-life balance where women are more involved in house holding responsibilities, raising children etc.

Table 4 Percentage of ATCOs currently experiencing stress

\begin{tabular}{|c|c|c|c|c|c|c|c|}
\hline & \multicolumn{6}{|l|}{ Stress } \\
\hline & & \multicolumn{3}{|l|}{ No } & \multicolumn{3}{|l|}{ Yes } \\
\hline & & Count & Row N \% & Column N \% & Count & Row N \% & Column N \% \\
\hline \multirow[t]{2}{*}{ Gender } & Male & 23 & $46.9 \%$ & $76.7 \%$ & 26 & $53.1 \%$ & $60.5 \%$ \\
\hline & Female & 7 & $29.2 \%$ & $23.3 \%$ & 17 & $70.8 \%$ & $39.5 \%$ \\
\hline
\end{tabular}

Table 5 show main stressors among ATCOs. Pressure, deadlines, fatigue and shiftwork are the main stressors among ATCOs. $63 \%$ of male ATCOs and 58\% for female reported that pressure as one of the main stressors, deadlines as seen affect more female ATCOs with $58.3 \%$ when for male it is only $38.8 \%$. Furthermore, the biggest concern is seen in fatigue with $69.4 \%$ for male ATCOs and $70.8 \%$ for female, shiftwork with $77.6 \%$ among male and $75.0 \%$ for female. Fewer percentages are seen in work relations with only $20.4 \%$ for male and $16.7 \%$ among female ATCOs.

Table 5 Main stressors among ATCOs

\begin{tabular}{|l|l|l|l|l|l|}
\hline \multicolumn{2}{|c|}{} & \multicolumn{4}{|l|}{ Gender } \\
\cline { 3 - 6 } \multicolumn{2}{|c|}{ Male } & Female \\
\cline { 3 - 6 } & Count & Column N \% & Count & Column N \% \\
\hline \multirow{2}{*}{ Pressure } & NO & 18 & $36.7 \%$ & 10 & $41.7 \%$ \\
\cline { 2 - 6 } & YES & 31 & $63.3 \%$ & 14 & $58.3 \%$ \\
\hline \multirow{2}{*}{ Deadlines } & NO & 30 & $61.2 \%$ & 10 & $41.7 \%$ \\
\cline { 2 - 6 } & YES & 19 & $38.8 \%$ & 14 & $58.3 \%$ \\
\hline \multirow{3}{*}{ Work relations } & NO & 39 & $79.6 \%$ & 20 & $83.3 \%$ \\
\cline { 2 - 6 } & YES & 10 & $20.4 \%$ & 4 & $16.7 \%$ \\
\hline \multirow{3}{*}{ Fatigue } & NO & 15 & $30.6 \%$ & 7 & $29.2 \%$ \\
\cline { 2 - 6 } & YES & 34 & $69.4 \%$ & 17 & $70.8 \%$ \\
\hline \multirow{2}{*}{ Shift work } & NO & 11 & $22.4 \%$ & 6 & $25.0 \%$ \\
\cline { 2 - 6 } & YES & 38 & $77.6 \%$ & 18 & $75.0 \%$ \\
\hline
\end{tabular}

Table 6 Descriptive statistics (mean; standard deviation)

\begin{tabular}{|l|l|l|l|}
\hline Stressor & Number & Mean & Standard. Deviation \\
\hline Pressure & 73 & 6164 &, 48962 \\
\hline Deadlines & 73 &, 4521 &, 50114 \\
\hline Work relations & 73 & 1918 &, 39643 \\
\hline Fatigue & 73 & 6986 &, 46203 \\
\hline Shift work & 73 &, 7671 &, 42559 \\
\hline
\end{tabular}

Mean for pressure is $(M=0,6164)$ with its standard deviation 0, 48962. Deadlines show its standard deviation as 0 , 50114 and mean $(M=0,4521)$. Work relations show lowest standard deviation 0, 39643 and its lowest mean score $(M=0,1918)$. This means that participants did not find work relations as a main source of stress. Fallowing, Fatigue with mean score 0, 6986 and Shift work with its highest score of 0, 7671. This means that participants recognized fatigue and shift work as major sources of stress.

As seen from the results gathered about stress, fatigue and shiftwork play a major role in causing stress. In order to lower stress level it is necessary to make further research on fatigue and main causes of fatigue among ATCOs. For this purpose questionnaire on fatigue was conducted on a same group of participants. 
Table 7 Opinion on invested effort by organization in development and implementation of new stress management strategies

\begin{tabular}{|l|l|l|l|l|l|}
\hline \multicolumn{2}{|c|}{} & Frequency & Percent & Valid Percent & $\begin{array}{l}\text { Cumulative } \\
\text { Percent }\end{array}$ \\
\hline \multirow{3}{*}{ Valid } & Lot of effort & 14 & 19,2 & 19,2 & 19,2 \\
\cline { 2 - 6 } & Not enough effort & 50 & 68,5 & 68,5 & 87,7 \\
\cline { 2 - 6 } & Not putting any effort & 9 & 12,3 & 12,3 & 100,0 \\
\cline { 2 - 6 } & Total & 73 & 100,0 & 100,0 & \\
\hline
\end{tabular}

ATCOs were asked to share their opinion on how much effort their ATC units are investing in development and implementation of new stress management strategies. The results are seen in Table 8 where majority (68.5\%) of controllers said that in their opinion organization is not putting enough effort in development and implementation of strategies that would help them overcome stress.

Table 8 Percentage of ATCOs currently experiencing fatigue and tiredness

\begin{tabular}{|l|l|l|l|l|l|}
\hline \multicolumn{2}{|c|}{} & \multicolumn{2}{|l|}{ Gender } \\
\cline { 3 - 6 } \multicolumn{2}{|c|}{} & Male & Female \\
\cline { 2 - 6 } & Count & Column N \% & Count & Column N \% \\
\hline $\begin{array}{l}\text { Are you currently experiencing } \\
\text { any problems with fatigue or } \\
\text { tiredness }\end{array}$ & NO & 13 & $31.0 \%$ & 5 & $16.1 \%$ \\
\cline { 3 - 6 } & & 29 & $69.0 \%$ & 26 & $83.9 \%$ \\
\hline
\end{tabular}

Table 9 Self-scoring fatigue question

\begin{tabular}{|c|c|c|}
\hline Statement & Mean $\mathrm{F}$ & Result F \\
\hline I feel that rotating shifts cause me to feel tired and less alert while at work & 4,6725 & Agree $57,2 \%$ \\
\hline I would perform better at work if I worked the same hours each day. & 3,3425 & Agree $39,7 \%$ \\
\hline I have worked shifts or mandatory overtime that did not allow me to get 8 hours of sleep between shifts. & 3,1781 & Neutral $30,1 \%$ \\
\hline I get on average 8 hours of sleep a night. & 2,2055 & Disagree $35,6 \%$ \\
\hline I perform better at work when I get 8 hours of sleep & 4,0548 & Agree $42,5 \%$ \\
\hline Receiving breaks every 2 hours greatly enhances my job performance & 4,0137 & Agree $58,9 \%$ \\
\hline I receive a break every two hours while on position & 2,6986 & Disagree $28,8 \%$ \\
\hline Someone at my facility has had an operation error/deviation that could be attributed to fatigue associated with rotating shifts, overtime or lack of breaks & 3,2329 & Agree $39,7 \%$ \\
\hline My motivation is lower when l'm fatigued & 4,1781 & Agree $47,9 \%$ \\
\hline Exercise brings on my fatigue & 2,3699 & Disagree $58,9 \%$ \\
\hline I am easily fatigued & 3,2466 & Neutral $42,5 \%$ \\
\hline Fatigue interferes with my physical functions & 4,0959 & Agree $57,5 \%$ \\
\hline Fatigue interferes with carrying out certain duties and resposibilities & 4,0274 & Agree $46,6 \%$ \\
\hline Fatige interferes with my work, family or social life & 4,1233 & Agree $46,6 \%$ \\
\hline I have problems with tiredness & 3,5479 & Agree $38,4 \%$ \\
\hline I have problems with concentration if i don't get enough sleep & 4,1781 & Agree $52,1 \%$ \\
\hline I make more mistakes when I am tired & 4,1233 & Agree $49,3 \%$ \\
\hline
\end{tabular}

Table 9 presents the highest scores for the question related to fatigue. Participants were able to choose one of five given answers (strongly disagree, disagree, neutral, agree, and strongly agree). Table above shows the highest scores on each question where we can see that on three questions highest score is disagree ( I get on average 8 hours of sleep a night (35.6\%); I receive brake every 2 hours while on position (28.8\%); exercise brings on my fatigue $(58.9 \%)$. I have worked shifts or mandatory overtime that did not allow me to get 8 hours of sleep between shifts $(30.1 \%)$ and I am easily fatigued $(42.5 \%)$ are answered as neutral. The rest of the statements had highest number of participants choosing agree; where the highest scored statement is "Receiving breaks every 2 hours greatly enhances my job performance" with $58.9 \%$.

Furthermore, one of the reasons of stress can be misbalance between work and private life. Table 10 shows significant misbalance between hours per week spent on work related activities and hours spent on household or social related activities, where mean for work related activities is 36.9589 hours a week with maximum of 80 hour per week and minimum of 0 hours. On the other side we can see that mean for household related activities is only 8.5890 , and social related activities come with lowest mean of 6.0685 hours per week.

Table 10 Average numbers of hours spent on household, social and work related activities

\begin{tabular}{|l|l|l|l|l|l|}
\hline Descriptive Statistics & N & Minimum & Maximum & Mean & Std. Deviation \\
\hline & 73 &, 00 & 48,00 & 8,5890 & 7,41214 \\
\hline Household related activities & 73 &, 00 & 20,00 & 6,0685 & 4,70912 \\
\hline Social related activities & 73 &, 00 & 80,00 & 36,9589 & 18,92635 \\
\hline Work related activities & 73 & & & & \\
\hline Valid N (listwise) & 73 & & & \\
\hline
\end{tabular}


This brings us to another question related to breaks and efficiency of breaks. ATCOs were asked how they usually spend their breaks and Figure 1 shows us final results of their answers. Each person was able to select more than one answer.

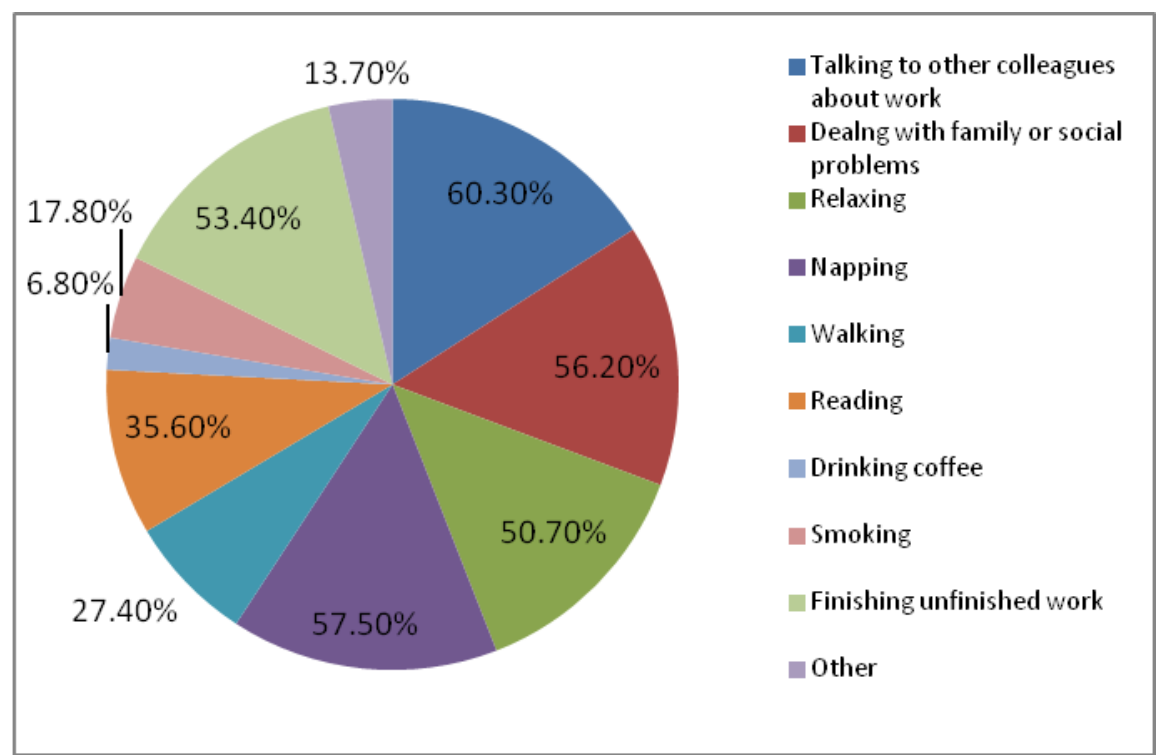

Fig 1 Use of breaks

Talking to other colleagues about work came out with $60.3 \%$, napping with $57.5 \%$, Dealing with family or social problems showed $56.2 \%, 53.4 \%$ is using their breaks to finish unfinished work, $50.7 \%$ controllers are relaxing etc. It is easy to notice that most of the controllers are not using breaks for relaxation in order to recuperate mental and physical stress or tiredness. These breaks are not used properly which brings up a question if ATC units are equipped with facilities that would allow ATCOs to use their beaks more efficiently. When asked, controllers gave their opinion which facilities would they like to have in their ATC unit they answered as fallowed: gym, library, massage, meditation room, sleeping room, garden, wireless internet excess etc. The purpose of this research was to find gaps where some small changes can be implemented in order to help ATCOs to manage their stress or fatigue.

\section{CONTRIBUTIONS OF THE SURVEY}

1. Research was able to highlight main stressors among air traffic controllers where pressure, fatigue and shiftwork came out with highest percentages

2. Opinion of ATCOs showed that there is an organizational problem with development of new strategies to overcome stress. This finding demand for further research of real situation in order to determinate is there a problem with organizational culture where employees are not informed of actions taken by organization or organization is really not noticing the importance of stress and fatigue prevention.

3. Misbalance between work and life activities shows the importance of proper shift scheduling as well as off duty time. If shifts are scheduled properly it would bring higher satisfaction of workers that are highly affected with this misbalance. Further research would be recommended on bigger sample of ATCOs worldwide.

4. Discovery on how breaks are not used efficient enough gave us a gap where some changes and improvements can be made. These changes could be made in environmental structure, where we could implement new facilities that would help ATCOs to recuperate mental and physical stress and fatigue.

5. Development of new tools for real time data collecting and monitoring would be useful for rest scheduling and maybe also shift scheduling, especially if these tools are supported with alertness system that would notified supervisors that certain employee on position excited the level of stress and/or fatigue and should use the break.

\section{CONCLUSION}

1. A major contribution of this paper is to help highlight the areas of research that are currently lacking such as efficiency of breaks and to encourage a collaborative effort to achieve a broader understanding of the causal factors for fatigue and stress in aviation as well as investigate how these factors interact. To fill this gap it is necessary to develop and validate methods to monitor the effectiveness of fatigue countermeasures introduced into ATC facilities. Identification of methods used for measuring air traffic controller cognitive and physical performance, and whether the measurement methods work effectively in both the laboratory and the 
operational setting. In order to get more accurate data on levels of stress and fatigue among ATCOs worldwide, as well as countermeasures taken by organization in reduction of stressors that are causing stress and fatigue it is recommended that research should be repeated on bigger sample.

2. Fatigue encompasses many different concepts and physiological and psychological states, it is important to evaluate fatigue with regard to all the situations that may cause an individual to become fatigued. An individual's personality could help identify who is more susceptible to fatigue, lapses due to workload or poor situation awareness, and their susceptibility towards monotony and fatigue. Tis survey only explored if air traffic controllers out and/or fatigued without establishing the level of stress and fatigue that they are currently experiencing. This could be achieved with further research using one of the measuring tools that are used in detection of stress and fatigue levels.

3. Fatigue management training should include basic information on sleep disorders and their treatment, where to seek help if needed, and any requirements relating to fitness for duty as well as meditational and relaxation training in practice in order to help individuals to get proper knowledge and skills that they can use further in life on their own.

4. Because the effects of sleep restriction are cumulative, schedules must be designed to allow periodic extended opportunities for recovery. Recovery opportunities need to occur more frequently when daily sleep restriction is greater, because of the more rapid accumulation of fatigue. 40-hour break starting at 20:00 would allow most people two consecutive nights of unrestricted sleep which would greatly help with accumulated fatigue.

5. Research has shown that most ATC units world-wide do not have psychologist or any type of therapist that is available for ATCOs around the clock. In the occupations with high level of stress, such as aviation industry where stress levels are higher than any other occupation presence of psychologist or any type of stress therapist is essential. If organization doesn't allow employment of an experts, organizations should consider developing a system that would in some degree replace work of psychologist or stress therapist.

6. While fatigue represents a significant risk in aviation when left unaddressed, there are currently numerous countermeasures and strategies that can be employed to increase safety. Furthermore, new technologies and countermeasures are being developed that hold great promise for the future. It is our hope that new countermeasures and strategies will serve to reduce the risk of aviation accidents and incidents attributable to the insidious effects of fatigue.

\section{REFERENCES}

[1] Palmer S., Definitions of Stress, Centre for Stress Management, London \& Edinburgh, London, 1999.

[2] Cox T.,Griffiths A., The nature and measurement of work stress: theory and practice. In J. R. Wilson, \& E. N. Corlett (Eds.), Evaluation of human work: A practical ergonomics methodology (2nd edn., pp. 783-803)., 1995 London, UK: Taylor \& Francis.

[3] Dewe P. J., O־Driscoll M. P., Cooper C. L., Coping with work stress: A review and critique. West Sussex, UK, 2010.

[4] Costa G., Fatigue and biological rhythms, in D.J. Garland J.A. Wise, and V.D. Hopkin (Eds), Handbook of Aviation Human Factors, Mahwah, NJ: Lawrence Erlbaum Associates, Inc., pp. 235-255., 1999.

[5] Meyer R.E. Stress and the air traffic controller. Revue de Médecine Aéronautique et Spatiale, 49, 1973, 97-106.

[6] Cruz C., Della Rocco. P, Investigation of sleep patterns among air traffic control specialists as a function of time off between shifts in rapidly rotating work schedules. Proceedings of the Eighth International Symposium on Aviation Psychology, 2, 1995, 974-979.

[7] Grandjean E.P., Wotzka G., Schaad R., and Gilgen A., Fatigue and stress in air traffic controllers, in K. Hashimoto, K. Kogi, and E. Grandjean (Eds). Proceedings of the Symposium held in Kyoto, Japan, September 29-30, 1969. London: Taylor \& Francis Ltd., 1971.

[8] Rhodes W., Heslegrave R., Ujimoto K.V., et al. Impact of shiftwork and overtime on air traffic controllers - Phase II: Analysis of shift schedule effects on sleep, performance, physiology and social issues. Final report TP 12816E, Transportation Development Centre, Transport Canada, 1996.

[9] Luna T.D., Air traffic controller shiftwork: What are the implications for aviation safety? A review. Aviation, Space, and Environmental Medicine, 68(1), 1997, 69-79.

[10] Wickens, C.D., Mavor, A.S., and McGee, J.P., Flight to the future. Human factors in air traffic control. Washington, National Academy Press, 1997.

[11] Benson A.J., Technical evaluation report on AGARD aerospace medical panel specialist meeting on rest and activity cycles for the maintenance of efficiency of personnel concerned with military flight operations. Advisory Group for Aerospace Research and Development, NATO, 1970.

[12] Costa, G. Evaluation of workload in air traffic controllers. Ergonomics, 36(9), 1993, 1111-1120.

[13] Hopkin, V.D., Human factors in air traffic control, London, Taylor \& Francis, 1995.

[14] Rhodes, W., Szlapetis I., Hahn, K., Heslegrave, R., Ujimoto K.V., A study of the impact of shiftwork \& overtime on air traffic controllers - Phase I: Determining appropriate research tools and issues. Final report TP 12257E, Transportation Development Centre, Transport Canada, 1994.

[15] Costa G., Schallenberg G., Ferracin, A., Gaffuri E., Psychophysical conditions of air traffic controllers evaluated by the standard shiftwork index. Work \& Stress, 9(2/3), 1995, 281-288.

[16] IATA, Fatigue risk management system, Implementation guide for operators, $1^{\text {st }}$ edition, July 2011

[17] Federal Aviation Administration National plan for aviation human factors, Volume 2. Report No. PB91-100347, Federal Aviation Administration, Washington, D.C., 1990.

[18] Gaillard A., Fatigue assessment and performance protection.Operator Functional State, IOS Press, 2003, 24-35.

[19] Gaillard A., W. K., Stress, workload, and fatigue as three biobehavioral states: A general view. In P. A. Hancock, \& P. A. Desmond (Eds.), Stress, workload, and fatigue (pp. 623639). Mahwah, New Jersey: Lawrence Erlbaum Associates, 2001. 
[20] Stein E.S, Human operator workload in air traffic control. Smolensky, M.W., Stein, E.S. eds. Human factors in air traffic control , Academic Press, 1998, 155-183.

[21] Tepas D. I., Price, J. M., What is stress and what is fatigue? In P. A. Hancock \& P. A. Desmond (Eds.), Stress, workload and fatigue. NY: Lawrence Elbaum, 2000.

[22] Toohey J, 'Managing the stress phenomenon at work' in Cotton P (Ed.), Psychological Health in the Workplace: Understanding and Managing Occupational Stress, The Australian Psychological Society, 1995.

[23] Della Rocco, P. and Cruz C., Shift work, age, and performance: investigation of the 2-2-1 shift schedule used in air traffic control facilities I. The sleep/wake cycle, Final report DOT/FAA/AM-95/19, Office of Aviation Medicine, Federal Aviation Administration, U.S. Department of Transportation, Washington, D.C, 1995 